\title{
Analyzing the effects of body image on college students' self- esteem, exercise flow, and psychological well-being
}

\author{
Boo-Gil Seok, Assistant professor, Department of Business Administration, Halla University, 28 Halladaegil \\ Wonju, 26404 Korea \\ *Hyun-Suk Park, Assistant Professor, Division of Liberal Arts, Halla University, 28 Halladaegil Wonju, \\ 26404 Korea, gardencityny97@gmail.com \\ * Corresponding author
}

\begin{abstract}
The present study was conducted for the purposes of analyzing how college students' perceived body image, who are engaged in sports activities, influences self-esteem, exercise flow, and psychological well-being and examining their correlations. Furthermore, this study intends to contribute to the sports industry by providing objective evidence of how being engaged in sports activities actually facilitate self-esteem and psychological well-being. A questionnaire survey was created to collect data based on the question items used in the previous studies. A total of 280 questionnaires were distributed to college students who had experience participating in sports activities or are currently participating. Eliminating incomplete questionnaires, 256 questionnaires were analyzed. Frequency analysis, correlation analysis, and regression analysis were carried out. The results are as follows: 1) Perceived body image of college students involved in sports activities positively affects psychological well-being. 2) Perceived body image has a positive effect on self-esteem, 3) Perceived body image positively influences exercise flow, 4) Self-esteem has a positive impact on exercise flow, and 5) Self-esteem shows a positive effect on psychological well-being. To confirm the physical and psychological effects of being engaged in sports activities, more elaborate research models are required to explore and explain deeper relations between the variables of this study.
\end{abstract}

Keywords: Body Image, Self-Esteem, Exercise Flow, Psychological Well-Being Received: 07.12.2020 Accepted: 17.01.2021 $\quad$ Published: 05.02.2021

\section{INTRODUCTION}

In modern society, physical appearance is perceived as one of the competitive power, forcing college students in their 20s to more concern about their body and appearance establishing either positive or negative image of themselves. As young adults become obsessive about their appearance, they may have a distorted thought about their body shape and appearance, which triggers psychological issues such as depression and anxiety when they feel overly dissatisfied with their body and appearance.

Body image is the perception that a person has of their body and it is quite subjective and internal interest that a person has of their appearance based on external criteria which are usually set by other people, society, and culture. During the period of puberty and adolescent, people usually establish the perception about their own body. As young adults, college students are also vulnerable to criticism and how others think about them. Therefore, it is very important for college students to have healthy and sound thoughts about their body, that is, to have a positive body image of themselves. Participating in spots activities can be one of the effective ways to form a positive body image[1], a positive body image established through sports becomes the driving force to make them continue enjoying sports[2]. Furthermore, establishing a positive body image through sports improves one's self-esteem[3].

Self-esteem is connected to the self-evaluation which can be either positive or negative, and it basically means to what extent people think they are valuable and a degree of self-respect they have of themselves[4]. Self-esteem motivates people and makes them push forward with challenges. Self-esteem can be built and fostered through sports. When actively participating in sports activities, people feel healthy and become more energetic, which leads to psychological happiness and in turn help them to improve their life quality. To obtain positive effects physically and psychologically, it is necessary to continue being engaged in sports and exercise flow can be required[5].

Flow refers to the state that a person becomes to have optimal experience by wholly concentrate on something[6], and exercise flow is the spiritual state that pushes a person to continue sports activities[7]. As the level of exercise flow increases, psychological stability and happiness increase.

People experience psychological well-being when positive and negative feelings are in good balance[8]. It is remarkable that psychological well-being can be improved by sports[9]. 
There have been many previous studies on self-esteem, exercise flow, and psychological well-being. However, scarcely has research been done on integrating these variables and examining the relationships between them. Therefore, this study tries to investigate the relationships between self-esteem, exercise flow, and psychological well-being and ultimately contribute to the growth of sports industry.

\section{Methods}

\subsection{Participants}

The population of this research is college students who have been and/or are presently involved in sports activities. The questionnaires were distributed and collected both online and offline. When gathering data offline, the questionnaires were distributed and collected by two trained research assistants. A total of 256 questionnaires were used for the final analysis. The participants' demographic characteristics are summarized in [Table 1].

Table 1 Overview of participants

\begin{tabular}{|c|c|c|c|}
\hline Items & Categories & $\mathrm{N}$ & $\%$ \\
\hline \multirow[t]{2}{*}{ Gender } & Male & 154 & 60.2 \\
\hline & Female & 102 & 39.8 \\
\hline \multirow[t]{4}{*}{ Department } & Humanities and Social Sciences & 106 & 41.4 \\
\hline & Engineering & 70 & 27.3 \\
\hline & Arts and Physical Education & 68 & 26.6 \\
\hline & Etc. & 12 & 4.7 \\
\hline \multirow[t]{4}{*}{ Grade } & Freshman & 30 & 11.7 \\
\hline & Sophomore & 88 & 34.4 \\
\hline & Junior & 75 & 29.3 \\
\hline & Senior & 63 & 24.6 \\
\hline \multirow{4}{*}{$\begin{array}{l}\text { Frequency } \\
\text { participation } \\
\text { sports }\end{array}$} & 1-2 times a week & 121 & 47.3 \\
\hline & 3-4 times a week & 83 & 32.4 \\
\hline & 5-6 times a week & 43 & 16.8 \\
\hline & Everyday & 9 & 3.5 \\
\hline
\end{tabular}

\subsection{Research model and Hypothesis}

The research model and the hypothesis to fulfil the purposes of this study are presented below.

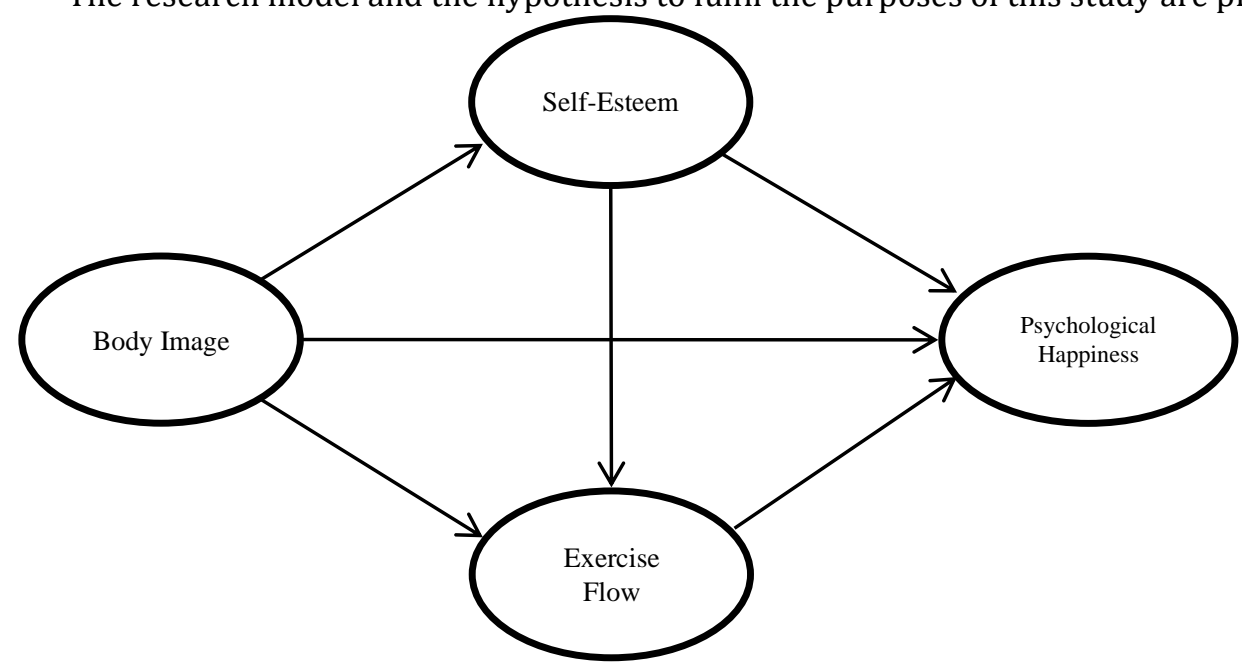

Figure 1. Research model

H1. College students' perceived body image positively influences psychological well-being.

H2. College students' perceived body image positively influences self-esteem.

H3. College students' perceived body image positively influences exercise flow. 
H4. Self-esteem positively influences exercise flow.

H5. Self-esteem positively influences psychological well-being.

H6. Exercise flow positively influences psychological well-being.

\subsection{Instruments}

A questionnaire survey was conducted for this study and the question items used were based on various previous studies. The survey includes four variables, which are body image, self-esteem, exercise flow, and psychological well-being. A 5-point Likert scale was used to measure each variable. A total of four questions asking demographic information are also included. The session dealing with body image consists of 15 question items[10]. Self-esteem is measured with ten question items[11]. For both exercise flow and psychological well-being, six question items are included, respectively[12][13]. All the question items are the ones used in the previous studies after being revised and modified.

\subsection{Data Analysis}

All statistical calculations for this study were made using PASW18.0. For the demographic characteristics of the participant, frequency analysis was employed and to find out correlation and multicollinearity of each variable, correlation analysis was employed. To test the hypothesis of this study, simple regression analysis was done.

\subsection{Reliability and Validity of Research Measures}

The content validity was confirmed by two experts in the field of sports before distributing questionnaires. With the exploratory factor analysis, construct validity was confirmed. Using the principal component analysis and a varimax rotation, the factors were combined and the factors which have eigenvalue of more than one were included. As a results, it turned out that body image consists of three sub-factors, and self-esteem, exercise flow, and psychological well-being are composed of a single factor, respectively. To obtain the inner consistencies, Cronbarch's $\alpha$ was calculated. Three sub-factors of body image fall between .839 and .904 , and self-esteem, exercise flow, and psychological well-being are $.864, .876, .868$, respectively. In sum, the statistical calculations show that the questionnaire used for this study is adequate[14].

Table 2 Overview of Exploratory Factor Analysis

\begin{tabular}{llll}
\hline Factors of body image & 1 & 2 & 3 \\
\hline 1. Appearance-oriented attitude & .882 & .021 & .169 \\
& .880 & .055 & -.033 \\
& .875 & .045 & .078 \\
& .865 & .105 & -.050 \\
& .735 & .047 & .078 \\
\hline 2. Body satisfaction & .118 & .869 & .257 \\
& .128 & .852 & .277 \\
& .058 & .779 & .118 \\
& -.087 & .630 & .377 \\
& .141 & .617 & .497 \\
& .058 & .084 & .781 \\
& .165 & .242 & .745 \\
& -.117 & .348 & .693 \\
& -.063 & .496 & .679 \\
\hline Total Appearance evaluation & .248 & .429 & .654 \\
\hline$\%$ of variance & & & \\
\hline Cumulative $\%$ & 5.830 & 3.472 & 1.101 \\
\hline Cronbarch's $\alpha$ & 38.869 & 23.145 & 7.337 \\
\hline$\chi^{2}=2534.124, d f=105, p=.000, K M O=.874$ & 38.869 & 62.014 & 69.351 \\
\hline
\end{tabular}

\section{Results and Discussion}

\subsection{The Prior Procedure of Hypothesis Test}

To verify the research model and the hypothesis, three sub-factors of body image were modified as a single factor to obtain the continuity and stationarity. After this modification, the correlation analysis and the regression analysis were carried out.

\subsection{The Results of Correlation Analysis}


Before carrying out the regression analysis, the correlations of each variables were checked with Pearson product-moments correlation coefficient to find out the correlations and directions among the variables. It was confirmed that all the variables have statistically significantly positive relations. In addition, the correlation coefficient was measured less than .80 which indicates that each variables is independent. This result also explains that the proper multicollinearity is confirmed.

Table 3 Correlations of Variables

\begin{tabular}{|c|c|c|c|c|}
\hline Variables & 1 & 2 & 3 & \\
\hline 1. Body image & 1 & & & \\
\hline 2. Self-esteem & $.344^{* * *}$ & 1 & & \\
\hline 3. Exercise flow & $.203^{* *}$ & $.623^{* * *}$ & 1 & \\
\hline 4. Psychological well-being & $.208^{* *}$ & $.434^{* * *}$ & $.657^{* * *}$ & 1 \\
\hline
\end{tabular}

\subsection{The results of hypothesis verification}

The results of verifying each hypothesis are as follows:

First, the results of simple linear regression analysis show that body image has a positive effect on psychological well-being $(F=11.532, p<.01, t=3.396, p<.01)$. Therefore, Hypothesis 1 is approved.

Table 4 Verification of Hypothesis 1

\begin{tabular}{lllll}
\hline Variable & $B$ & $S . E$. & $\beta$ & $t$ \\
\hline (Constant) & 3.481 & .212 & & $16.414^{* * *}$ \\
\hline Body image & .215 & .063 & .208 & $3.396^{* *}$ \\
\hline$R^{2}=.043, F=11.532^{* *},{ }^{* *} p<.01,{ }^{* * *} p<.001$ & & & \\
\hline
\end{tabular}

Second, the results of simple linear regression analysis show that body image has a positive effect on self-esteem $(F=34.102, p<.001, t=5.840, p<.001)$. Therefore, Hypothesis 2 is approved.

Table 5 Verification of Hypothesis 2

\begin{tabular}{lllll}
\hline Variable & $B$ & $S . E$. & $\beta$ & $t$ \\
\hline (Constant) & 2.371 & .251 & & $9.444^{* * *}$ \\
\hline Body image & .437 & .075 & .344 & $5.840^{* * *}$ \\
\hline$R^{2}=.118, F=34.102^{* * *},{ }^{* * *} p<.001$ & & & \\
\hline
\end{tabular}

Third, the results of simple linear regression analysis show that body image has a positive effect on exercise flow $(F=10.877, p<.01, t=3.298, p<.01)$. Therefore, Hypothesis 3 is approved.

Table 6 Verification of Hypothesis 3

\begin{tabular}{lllll}
\hline Variable & $B$ & $S . E$. & $\beta$ & $t$ \\
\hline (Constant) & 3.502 & .196 & & $17.869^{* * *}$ \\
\hline Body image & .193 & .058 & .203 & $3.298^{* *}$ \\
\hline$R^{2}=.041, F=10.877^{* *},{ }^{* *} p<.01,{ }^{* * *} p<.001$ & & & \\
\hline
\end{tabular}

Forth, the results of simple linear regression analysis show that self-esteem has a positive effect on exercise flow $(F=161.357, p<.001, t=12.703, p<.001)$. Therefore, Hypothesis 4 is approved.

Table 7 Verification of Hypothesis 4

\begin{tabular}{lllll}
\hline Variable & $B$ & S.E. & $\beta$ & $t$ \\
\hline (Constant) & 2.359 & .142 & .623 & $16.570^{* * *}$ \\
\hline Self-esteem & .467 & .037 & & $12.703^{* * *}$ \\
\hline$R^{2}=.388, F=161.357^{* * *},{ }^{* * *} p<.001$ & & & \\
\hline
\end{tabular}

Fifth, the results obtained from simple linear regression analysis show that self-esteem has a positive effect on psychological well-being $(F=58.819, p<.001, t=7.669, p<.001)$. Therefore, Hypothesis 4 is approved. 
Table 8 Verification of Hypothesis 5

\begin{tabular}{lllll}
\hline Variable & $B$ & $S . E$ & $\beta$ & $t$ \\
\hline (Constant) & 2.849 & .178 & & $16.033^{* * *}$ \\
\hline Self-esteem & .352 & .046 & .434 & $7.669^{* * *}$ \\
\hline$R^{2}=.188, F=58.819^{* * *},{ }^{* * *} p<.001$ & & & \\
\hline
\end{tabular}

Sixth, the results of simple linear regression analysis show that exercise flow has a positive effect on psychological well-being $(F=193.321, p<.001, t=13.904<.001)$. Therefore, Hypothesis 4 is approved. Table 9 Verification of Hypothesis 6

\begin{tabular}{lllll}
\hline Variable & $B$ & $S . E$. & $\beta$ & $t$ \\
\hline (Constant) & 1.243 & .214 & & $5.820^{* * *}$ \\
\hline Exercise flow & .712 & .051 & .657 & $13.904^{* * *}$ \\
\hline$R^{2}=.432, F=193.321^{* * *},{ }^{* * *} p<.001$ & & & \\
\hline
\end{tabular}

\subsection{Discussion}

Physical activity positively affect the improvement of mental health[15]. One of the previous studies, which examines the relationships between body image and psychological well-being among adults who are engaged in ballet courses, concluded that body image positively influence psychological well-being[16]. The results obtained from this study echo those from previous studies.

A positive body image formed while participating in sports enhances self-esteem and exercise flow. Various studies previously done concluded that when people perceive their body more positively, they have higher self-esteem and also body image and exercise flow affect each other[17][18][19]. Therefore, it is necessary to encourage people to get engaged in sports.

Self-esteem influences both exercise flow and psychological well-being positively[20]. The higher self-esteem people have, the more they become engaged in sports and in turn the psychological wellbeing increases more. Considering a higher self-esteem people have, the more interest they have in their health[21], the more confident they become, and the more easily adapt themselves to their surrounds[4], it is crucial to encourage college students to get engaged in sports so that they become able to enhance their self-esteem. Hence, various programs which foster self-esteem need to be developed.

Exercise flow positively affects psychological well-being. The results obtained from this study mirror those of the previous studies[20][22-34]. When the level of flow increases through the active participation in sports, As actively participating in sports, various needs can be fulfilled[35].

\section{Conclusion}

This research was carried out to scrutinize the relationships between body image, psychological well-being, self-esteem, and exercise flow. The results show that 1) Perceived body image of college students engaged in sports positively impacts psychological well-being, self-esteem, and exercise flow. 2) Self-esteem has positive relationships with exercise flow and psychological well-being. 3) Exercise flow positively affects psychological well-being.

Overall, the findings of this study are meaningful in that they explain with insights how self-esteem, exercise flow can be fostered, ultimately resulting in happiness enhancement. Despite the meaningful findings and academic contributions to the field, however, it is suggested that further studies ex It is suggested that to reach a fuller understanding of the relationships of body image, self-esteem, exercise flow, and psychological well-being and how they influences one another, further studies need to look more closely and extensively at them.

\section{References}

[1] Igbang, J. E. and S. Gutin. (1978) Society and the adolescent self-image, Princeton University Press, New Jersey, USA.

[2] Kim, S. H. (2010) A study on the relationship between the elderly participation to line dance and physical self-concept and subjective well-being. Ph.D. Dissertation, Mokpo National University, Korea. Available from http://www.riss.kr/link?id=T13067945

[3] Keeton, W. P., Cash, T. F. and Brown, T. A. (1990) Body image of body image? Comparative multidimensional assessment among college students. Journal of Personality Assessment 54(2), 213-230.

[4] Rosenberg, M. (1979) Conceiving the self, Basic Books, New York.

[5] Baek, H. and Shim, S. S. (2011) Analysis of causal model on the leisure experience, leisure function, flow 
experience and sport continuance intention of leisure sports participants. Korean Journal of Physical Education 50(6), 337-352. Available from: http://www.riss.kr/link?id=A106546976

[6] Csikszentmihalyi, M. (1975) Beyond boredom and anxiety. Jossey-Bass Publishers, San Francisco, USA.

[7] Scanlan, T. K., and Lewthwaite, R. (1986) Social psychological aspects of competition for mail youth sports participants: IV. Predictors of enjoyment. Journal of Sport Psychology 8, 25-35.

[8] Bradburn, N. M. (1969) The structure of psychological well-being, Aldine, Oxford, England.

[9] Min, K. H. and Kim, S. K. (2008) The causal relationship between leisure activities and leisure satisfaction, and psychological well-being in professional soldiers. Korean Journal of Leisure, Recreation \& Park 32(4), 2132. Available from: http://www.dbpia.co.kr/journal/articleDetail?nodeId=NOED07586481

[10] Cash, T. F. (1990) The multidimensional body-self relations questionnaire, In appendix. Body Image Disturbance, Assessment and Treatment (Thompson, J. K.), Pergamon Press, New York, USA.

[11] Cooperasmith, S. (1967) The antecedents of self-esteem. W. H. Freeman \& Co., San Francisco, USA.

[12] Omodei, M. M. and Wearing, A. J. (1990) Need satisfaction and involvement in personal project: Toward an integrative model of subjective well-being. Journal of Personality and Social Psychology 59(4), 762-769.

[13] Ryff, C. (1989) Happiness is everything, or is it? Explorations on the meaning of psychological wellbeing. Journal of Personality and Social Psychology 57(6), 1069-1081.

[14] Nunnally, J. C. (1978) Psychological theory. McGraw-Hill, New York.

[15] Layman, E. M. (1972) The contribution of play and sports to emotional health. In Kane, J. E.(Ed). Psychological aspects of physical education and sport, Lopez, S. J. and Snyder, C. R. (2003) Positive psychological assessment

[16] Shin, W. N. (2019) Relations among physical image, emotional expressiveness, and psychological happiness of adult ballet participants. Master's Thesis. Yonsei University, Korea. Available from: http://www.riss.kr/link?id-T15520823

[17] Sonstroem, R. J. and Morgan, W. P. (1989) Exercise and self-esteem: Rationale and model. Medicine and Science in Sport and Exercise 21(3), 329-337.

[18] Lee, J. M. (2019) The relationships between class satisfaction, body image, self-esteem and adherence intention of students participated liberal dance class. Korean Journal of Dance 19(1), 1-13. Available from: http://www.dbpia.co.kr/pdf/cpViewer

[19] Kim, J. Y., Yoon, I. A. and Joo, H. C. (2013) The structural relationships among body image, selfefficacy and dance flow of dancesport players. Journal of Coaching Development 15(3), 107-117. Available from: http://www.dbpia.co.kr/journal/articleDetail?nodeId=NODE02263382

[20] Kim, H. J., Seol, S. H. and Yoon, Y. J. (2013) The relationship among golf participants' self-esteem, flow and psychological well-being. Journal of Coaching Development 15(4), 85-92. Available from: http://www.dbpia.co.kr/journal/articleDetail?nodeId=NODE02360363

[21] Kim, Y. R. (2005) The relationship among the types of leisure activity, activities of daily living and self-esteem of the elderly. Korean Journal of Physical Education 44(6), 183-192. Available from: http://kiss.kstudy.com/thesis/thesis-view.asp?key=3718955

[22] Kim, H. J., Yoon, Y. J. and Cho, N. H. (2014) The influence of coaching behaviour patterns of golf instructors on exercise flow and psychological happiness. Journal of Sport and Leisure Studies 57(1), 4554. Available from: http://www.dbpia.co.kr/journal/articleDetail?nodeId=NOED06246120

[23] Bhoi, A. K., Sherpa, K. S., \& Khandelwal, B. (2018). Arrhythmia and ischemia classification and clustering using QRS-ST-T (QT) analysis of electrocardiogram. Cluster Computing, 21(1), 1033-1044.

[24] Reddy, A. V., Krishna, C. P., \& Mallick, P. K. (2019). An image classification framework exploring the capabilities of extreme learning machines and artificial bee colony. Neural Computing and Applications, $1-21$.

[25] Bisoy, S. K., Mallick, P. K., \& Mishra, A. Fairness Analysis of TCP Variants in Asymmetric Network. International Journal of Engineering \& Technology, 7(2.12), 231-233.

[26] Mallick, P. K., Mishra, D., Patnaik, S., \& Shaw, K. (2016). A semi-supervised rough set and random forest approach for pattern classification of gene expression data. International Journal of Reasoningbased Intelligent Systems, 8(3-4), 155-167.

[27] Mallick, P. K., Mohanty, B. P., \& Jha, S. A novel approach using. Supervised and Unsupervised Learning" to prevent the adequacy of Intrusion Detection Systems", International Journal of Engineering \& Technology, 7(3.34), 474-479.

[28] Satapathy, S. K., Mishra, S., Sundeep, R. S., Teja, U. S. R., Mallick, P. K., Shruti, M., \& Shravya, K. (2019). Deep learning based image recognition for vehicle number information. International Journal of Innovative Technology and Exploring Engineering, 8, 52-55.

[29] Mallick, P. K., Kar, S. K., Mohanty, M. N., \& Kumar, S. S. (2015). Use of histogram approach in color band detection for electrical passive component. International Journal of Applied Engineering 
Research, 10(44), 31446-31450.

[30] Mishra, S., Mallick, P. K., Tripathy, H. K., Bhoi, A. K., \& González-Briones, A. (2020). Performance Evaluation of a Proposed Machine Learning Model for Chronic Disease Datasets Using an Integrated Attribute Evaluator and an Improved Decision Tree Classifier. Applied Sciences, 10(22), 8137.

[31] Bhoi, A. K., Sherpa, K. S., \& Mallick, P. K. (2014, April). A comparative analysis of neuropathic and healthy EMG signal using PSD. In 2014 International Conference on Communication and Signal Processing (pp. 1375-1379). IEEE.

[32] Bhoi, A. K., Sherpa, K. S., Khandelwal, B., \& Mallick, P. K. (2019). T Wave Analysis: Potential Marker of Arrhythmia and Ischemia Detection-A Review. In Cognitive Informatics and Soft Computing (pp. 121130). Springer, Singapore.

[33] Mishra, S., Mallick, P. K., Jena, L., \& Chae, G. S. (2020). Optimization of Skewed Data Using SamplingBased Preprocessing Approach. Frontiers in Public Health, 8.

[34] Bhoi, A. K., \& Sherpa, K. S. (2016). Statistical analysis of QRS-complex to evaluate the QR versus RS interval alteration during ischemia. Journal of Medical Imaging and Health Informatics, 6(1), 210-214.

[35] Tinsley, H. E. and Tinsley, D. J. (1986) A theory of the attributes, benefits and causes of leisure experience. Leisure Science 8(1), 1-45. 